\title{
Jalecos de trabalhadores de saúde: um potencial reservatório de microrganismos
}

\author{
Healthcare workers coats: a potential reservoir of microorganisms
}

\author{
Adriana C. de Oliveira' ${ }^{1}$ Marlene das Dores M. Silva ${ }^{2}$
}

\begin{abstract}
RESUMO
Objetivou-se determinar as características epidemiológicas de microrganismos presentes nos jalecos de trabalhadores de saúde em um hospital de grande porte. Tratou-se de um estudo transversal conduzido no período de janeiro a agosto de 2011. Realizou-se a rolagem de swabs no bolso e região do abdômen do jaleco. Foi realizada estatística descritiva e teste qui-quadrado de Pearson. Participaram do estudo 100 profissionais. Foram obtidas 200 amostras dos jalecos. Dessas 47\% foram positivas com crescimento microbiano, $73,6 \%$ apresentaram resistência a um ou mais antimicrobiano sendo $55,7 \%$ nos bolsos e $44,3 \%$ na região abdominal. A recuperação do Staphylococcus ssp nas duas áreas analisadas com resistência a vários antimicrobianos, dentre eles a oxacilina mereceu destaque. A maior contaminação foi verificada entre jalecos dos profissionais de enfermagem $(p<0,05)$. Os jalecos de trabalhadores de saúde podem tornar-se contaminados por microrganismos de relevância epidemiológica, contribuindo, para a possível disseminação de patógenos entre diferentes pacientes e ambientes.
\end{abstract}

Palavras-chave: Infecção Hospitalar. Vestuário. Trabalhadores de saúde.

\begin{abstract}
The objective was to determine the epidemiological characteristics of microorganisms present in the healthcare workers coats in a large hospital. It was a cross-sectional study carried out from January to August 2011. The samples were obtained by swabs from the pocket and abdominal region of professionals' coats. Data were analyzed by descriptive statistics and chi-square test. The study included 100 professionals. We obtained 200 samples of coats. Of these $47 \%$ were positive with microbial growth, $73.6 \%$ showed resistance to one or more antimicrobials being $55.7 \%$ in the pockets and $44.3 \%$ in the abdominal region. The most important was the recovery of Staphylococcus spp in the two analyzed areas with resistance to various antibiotics, including oxacillin. The highest contamination was observed between nursing professionals coats $(p<0.05)$. The coat of healthcare workers can become contaminated by microorganisms of epidemiological relevance, contributing to the potential spread of pathogens between patients and different environments.
\end{abstract}

Keywords: Cross Infection. Clothing. Health Personnel.

1. Enfermeira. Professora Associada da Escola de Enfermagem da Universidade Federal de Minas Gerais. Pesquisador do CNPq. Líder do grupo de Pesquisa em Infecção Relacionada ao Cuidar em Saúde (NEPIRCS/CNPq).

2 Enfermeira. Mestranda do Programa de Pós-graduação em Enfermagem da Escola de Enfermagem da UFMG.
Correspondencia Adriana Cristina de Oliveira Escola de Enfermagem da UFMG Avenida Alfredo Balena, 190, Santa Efigência, MG

CEP: $30130-100$

Artigo recebido em 28/10/2014 Aprovado para publicação em 12/02/2015 


\section{Introdução}

As infecções relacionadas à assistência à saúde (IRAS) são definidas como aquelas adquiridas durante a prestação dos cuidados de saúde, cuja disseminação frequentemente ocorre pela contaminação cruzada. ${ }^{1}$

A Organização Mundial de Saúde (OMS) considera que 5 a $15 \%$ de todos os pacientes hospitalizados adquirem IRAS. Nos Estados Unidos, estima-se que cerca de dois milhões de casos de IRAS ocorram anualmente, ocasionando cerca de 60 a 90 mil mortes e mais de cinco milhões de dólares gastos. ${ }^{1}$

No Brasil, não se dispõe de dados sistematizados sobre a ocorrência das IRAS e seu custo, apesar de $80 \%$ dos hospitais do país possuírem Comissão de Controle de Infecção Hospitalar (CCIH), somente $40 \%$ destes tem indicadores confiáveis, possivelmente pela diversidade de metodologias utilizadas, interpretação e aplicação destas na coleta de dados. ${ }^{2}$

As IRAS são consideradas em todo o mundo como um importante problema de saúde pública, por comprometerem a segurança e a qualidade assistencial dos pacientes em instituições de saúde, sendo que quando relacionadas a microrganismos resistentes aumentam ainda mais os custos institucionais, o período de internação e, sobretudo, as taxas de mortalidade e morbidade. ${ }^{1,3}$

O controle das IRAS e da disseminação de microrganismos torna-se um desafio nas instituições de saúde devido às importantes complicações relacionadas à assistência ao paciente. ${ }^{4}$

A principal via de transmissão de microrganismos implicados na ocorrência das IRAS ocorre pelas mãos dos trabalhadores de saúde e pacientes. No entanto, a possível participação de fatores ambientais como, superfícies, equipamentos e jalecos dos trabalhadores como fonte de disseminação de microrganismos desperta a atenção de pesquisadores, da sociedade e das agências e associações de controladores de infecção. ${ }^{5,6}$

A recuperação de microrganismos em jalecos utilizados pelos trabalhadores de saúde tem constituído crescente fonte de preocupação, pela possibilidade de contaminação cruzada discutida e questionada pelos próprios profissionais e até mesmo pela sociedade. ${ }^{6,7}$

Fundamentando esta preocupação estudos apontam a contaminação nos jalecos dos trabalhadores de saúde em diversas regiões como bolsos, pu- nhos, região do abdômen, o que pode ser associada ao contato direto destes locais com as mãos dos profissionais, com o paciente durante o cuidado e contato indireto com fômites (superfícies ambientais, estetoscópios entre outros). Adicionalmente, assinalam a similaridade do perfil dos microrganismos de pacientes colonizados internados nas instituições hospitalares obtida por meio de testes moleculares às cepas isoladas de jalecos. ${ }^{8,9}$

Diante da importância do tema este estudo teve com objetivo determinar as características epidemiológicas de microrganismos presentes nos jalecos de trabalhadores de saúde em unidades de clínica médico-cirúrgica de um hospital de grande porte.

\section{Material e métodos}

Tratou-se de um estudo transversal conduzido no período de janeiro a agosto de 2011, em unidades de internação de clínica médico-cirúrgica de um hospital geral e filantrópico de grande porte localizado no interior de Minas Gerais.

O hospital possui 403 leitos, com média de ocupação de $88 \%$. É referência no sistema municipal e região centro-oeste do estado de Minas Gerais para o cuidado de pacientes portadores de patologias de média e alta complexidade como cirurgia cardíaca, transplante renal, radioterapia e quimioterapia, entre outros.

As unidades de internação onde se realizou o estudo atendem pacientes das clínicas (ortopedia, oncologia, cardiovascular, neurologia, transplante, gastrintestinal, urologia e outros) provenientes da comunidade, pronto-socorro municipal e de outros hospitais da cidade e região. Possuem 143 leitos distribuídos em três andares.

Nas três unidades de internação incluídas no estudo, a população elegível compreendeu todos os profissionais de saúde que realizavam assistência direta a pacientes estão assim distribuídos: $15(13,0 \%)$ fisioterapeutas, $15(13,0 \%)$ médicos, $19(16,0 \%)$ enfermeiros e $67(58,0 \%)$ técnicos de enfermagem.

Diante do total de $116(\mathrm{~N})$ indivíduos, calculou-se que para um nível de $95 \%$ os possíveis erros máximos de estimação (E) são iguais a 0,01 (1,0\%), 0,02 (2,0\%), 0,03 (3,0\%), 0,04 (4,0\%) e 0,05 (5,0\%). Utilizou-se uma amostra aleatória simples (AAS), cujo cálculo amostral levou em consideração as diferentes categorias profissionais, calculando a representatividade de cada categoria profissional em relação à po- 
pulação, com o objetivo de manter as mesmas proporções na amostra. Realizou-se o cálculo amostral a partir da determinação dos parâmetros descritos para a amostra aleatória simples e estratificada pela categoria profissional com poder de $80 \%$, intervalo de confiança de $95 \%$ e uma diferença estatística de $5 \%$.

A partir deste cálculo, teve-se como resultado um $n$ igual a 91. Este deveria ser o tamanho da amostra a ser coletada. O valor foi arredondado para 100, de forma a assegurar o resultado desejado. Finalmente, a amostra (população estudada) ficou composta de 12 médicos, 12 fisioterapeutas, 17 enfermeiros e 59 técnicos de enfermagem, totalizando 100 profissionais.

Considerou-se como critério para a inclusão dos participantes: realizar assistência direta a pacientes no período da coleta de dados. Excluíram-se aqueles que se encontravam em férias ou licença médica ou em período de experiência (data de admissão inferior a três meses) durante o período da coleta de dados. Fonoaudiólogo, psicólogo, técnico de laboratório não fizeram parte da amostra por não prestarem assistência direta a pacientes.

Todos profissionais que atenderam os critérios de inclusão foram convidados de forma individual e verbal a participarem do estudo. Após aceite destes, lhes foi apresentado o Termo de Consentimento Livre e Esclarecido (TCLE), explicitando os objetivos, a finalidade, a relevância da temática, além dos aspectos de confidencialidade, anonimato e da participação voluntária. Ressalta-se que não houveram recusas em participar do trabalho.

Para a coleta de dados foi elaborado um questionário para o momento da entrevista com os trabalhadores de saúde. O instrumento foi composto de questões fechadas, abordando características demográficas (sexo, idade, formação profissional, tempo de formação, tempo de trabalho na instituição, turno de trabalho no setor, número de empregos, demais locais de trabalho).

Após a realização da entrevista, procedeu-se a coleta das amostras microbiológicas dos jalecos no bolso e região do abdômen, por meio da técnica de rolagem de swabs (Swab Hast Plástico J.P). Estas áreas dos jalecos foram selecionadas em razão da frequência de toques pelas mãos dos profissionais e contato direto ou indireto com pacientes, conforme observado em estudos anteriores. ${ }^{6,8,9}$

Assim, foi rolado um swab estéril seco sobre o bolso e região do abdômen. Para os jalecos que apre- sentaram mais de um bolso definiu-se para a rolagem do swab apenas um destes, sendo no momento da coleta da amostra para análise microbiológica perguntado ao participante qual o bolso era mais utilizado.

Na região do abdômen delimitou-se a área próxima ao fechamento de botões, na parte central do abdome a fim de favorecer a análise da área de maior contato com paciente durante realização de procedimentos e com o ambiente/unidade do paciente.

Tão logo a rolagem do swab foi realizada, estes foram transferidos para tubos com meio de transporte Stuart e encaminhados ao laboratório de microbiologia da instituição de estudo, que realizou os testes necessários para a recuperação e definição do perfil de sensibilidade dos microrganismos quando presentes nas amostras.

As amostras foram obtidas no período diurno de 13:30 às 15:00 horas para profissionais que trabalham de 7:00 as 19:00 horas, no período noturno 22:30 às 24:00 horas para os profissionais que trabalham de 19:00 as 7:00 horas.

A semeadura de cada material coletado foi realizada nos meios de cultura ágar sangue de carneiro, ágar MaCConkey, ágar manitol salgado, ágar sabouraud e caldo de enriquecimento tioglicolato com indicador resarsurina. Todos os meios foram incubados em estufas a $35^{\circ} \mathrm{C}$ por 72 horas. ${ }^{10}$

Os microrganismos isolados nestes meios foram identificados quanto ao gênero e espécie, no sistema automatizado Vitek ${ }^{\circledR} 2$ (BioMérieux ${ }^{\circledR}$ ) e após esta etapa foi realizado o antibiograma, pelo método de difusão de discos (Bauer-Kirby®).

Todos os procedimentos de cultura, identificação e antibiograma seguiram as recomendações do Clinical and Laboratory Standards Institute (CLSI). ${ }^{10}$

Destaca-se que na instituição não havia armários para guarda dos jalecos, sendo os mesmos levados para casa pelos trabalhadores de saúde. A troca dos jalecos era realizada a critério do usuário.

Os dados foram analisados por meio da estatística descritiva, cálculo das frequências absolutas e relativas, aplicação do teste qui-quadrado de Pearson, utilizando-se nível de significância de 5\% ( $\mathrm{p}<0,05)$. Os dados coletados foram digitados no programa EPIINFO versão 3.3.2. Toda a análise foi realizada com auxílio do software Statistical Package for Social Science (SPSS) versão 15.0 e Stata versão 9.0.

O projeto fundamentou-se na Resolução 196/ 96 do Conselho Nacional de Saúde para pesquisas envolvendo seres humanos, vigente à época do estu- 
do, e foi submetido ao Comitê de Ética em Pesquisa para apreciação, sendo aprovado sob o número ETIC 0430.0.203.000-09.

\section{Resultados}

\section{Perfil demográfico dos trabalhadores que utilizam o jaleco}

Os 100 profissionais que participaram do estudo eram distribuídos nas seguintes categorias: $76 \%$ da equipe de enfermagem (enfermeiros, técnicos de enfermagem) e $24 \%$ médicos e fisioterapeutas (24\%).

Observou-se um predomínio do sexo feminino (66\%). A idade variou entre 19 e 65 anos com média igual a 30,8 e mediana de 28,5 anos.

Em relação ao tempo de formação profissional, 53\% tinham entre um e três anos e 50\% trabalhavam na instituição a menos de 17 anos.

O turno de trabalho da maioria dos entrevistados $(57 \%)$ foi diurno seguido daqueles profissionais que realizavam plantão em ambos os turnos (43\%).

Quanto ao número de empregos, $83 \%$ da amostra estudada declararam trabalhar somente na referida instituição, $17 \%$ reportaram possuir dois ou mais empregos. Os médicos foram os profissionais com maior número de empregos.

Considerando o tipo de serviço, a maioria $(70,6 \%)$ declarou trabalhar em unidades de atenção primária e pronto socorro e $29,4 \%$ em outros hospitais.

\section{Microrganismos presentes nas áreas analisadas dos jalecos de trabalhadores de saúde}

Foram coletadas 100 amostras da região dos bolsos do jaleco e 100 da região abdominal. Das 200 amostras coletadas, 94 (47\%) foram positivas após 72 horas de incubação e das amostras positivas, obteve-se 144 isolados bacterianos.

Na região do bolso, do total de 100 amostras, $51 \%$ apresentaram positividade, sendo os microrganismos isolados: Staphylococcus $\operatorname{ssp}(39,7 \%)$, Kocuria ssp $(8,4 \%)$, Micrococcus ssp (4,2\%), Streptococcus $\operatorname{ssp}(2,8 \%)$, Enterococcus faecalis $(0,7 \%)$ Serratia $\mathrm{ssp}$ $(0,7 \%)$, Acinetobacter baumannii $(0,7 \%)$.

Na área do abdômen, do total de 100 amostras, $43 \%$ foram positivas para os referidos microrganismos: Staphylococcus ssp (25,7\%), Micrococcus ssp $(10,4 \%)$, Kocuria ssp (2\%), Enterococcus faecalis
(2\%), Acinetobacter baumannii (2\%), Streptococcus $\operatorname{ssp}(0,7 \%)$,

O Staphylococcus ssp foi o gênero predominante nas duas áreas analisadas (bolso e abdômen), com recuperação de $57(39,7 \%)$ cepas nos bolsos e $37(25,7 \%)$ cepas na região do abdômen.

Dentre as espécies de Staphylococcus isoladas destacaram: Staphylococcus epidermidis (37,2\%), Staphylococcus hominis (29,8\%), Staphylococcus capitis (14,9\%), Staphylococcus haemolyticus $(11,7 \%)$, Staphylococcus warneri (4,2\%), Staphylococcus cohnii $(1,1 \%)$ e Staphylococcus aureus $(1,1 \%)$.

Os Staphylococcus coagulase negativa (SCN), Kocuria ssp, Streptococcus ssp, e Serratia ssp apresentaram-se em maior proporção nos bolsos.

Foi recuperada apenas uma cepa de Staphylococcus aureus no abdômen.

Acinetobacter baumannii, Enterococcus faecalis e Micrococcus ssp foram predominantes na região do abdômen.

A seguir, apresenta-se a distribuição dos profissionais participantes do estudo de acordo com as variáveis demográficas em relação à presença de microrganismos na área do bolso e região do abdômen em unidades de internação de clínica médico-cirúrgica (Tabela 1).

Observou-se diferença significativa $(\mathrm{p}<0,05)$ para a variável sexo e a maior contaminação na região do abdômen.

\section{Perfil de susceptibilidade dos microrganis- mos isolados dos jalecos dos trabalhado- res de saúde de unidades de internação aos antimicrobianos testados}

Dentre os isolados bacterianos, $106(73,6 \%)$ apresentaram resistência a um ou mais antimicrobianos testados.

Quanto aos microrganismos resistentes, 59 $(55,7 \%)$ foram recuperados dos bolsos e $47(44,3 \%)$ da região do abdômen.

Os Staphylococcus coagulase negativa (SCN) são frequentemente considerados contaminantes de pele, neste estudo estão destacados devido a sua relação com a ocorrência de infecções principalmente em pacientes imunocomprometidos e ao perfil de resistência à clindamicina $(30,7 \%)$, eritromicina $(55,3 \%)$, oxacilina $(36,2 \%)$, penicilina $(70,2 \%)$, sulfametoxazol/trimetoprina (24,5\%), sendo estes considerados de primeira escolha para o tratamento das infecções causas pelos SCN. 
Tabela 1: Distribuição dos trabalhadores participantes do estudo de acordo com as variáveis demográficas em relação à contaminação por microrganismos na área dos bolsos e região do abdômen, $(n=100)$, Divinópolis, 2011.

\begin{tabular}{|c|c|c|c|c|c|c|}
\hline \multirow[b]{2}{*}{ Variáveis } & \multicolumn{2}{|c|}{$\begin{array}{l}\text { Presença de microrganismos } \\
\text { na região do bolso }\end{array}$} & \multicolumn{3}{|c|}{$\begin{array}{l}\text { Presença de microrganismos } \\
\text { na região do abdômen }\end{array}$} & \multirow[b]{2}{*}{ Valor $p$} \\
\hline & $\begin{array}{r}\text { Sim } \\
\mathrm{n}(\%)\end{array}$ & $\begin{array}{r}\text { Não } \\
\mathrm{n}(\%)\end{array}$ & Valor $p$ & $\begin{array}{r}\operatorname{Sim} \\
\mathrm{n}(\%)\end{array}$ & $\begin{array}{r}\text { Não } \\
\mathrm{n}(\%)\end{array}$ & \\
\hline $\operatorname{Sexo}^{1}$ & & & 0,483 & & & 0,022 \\
\hline Feminino & $32(62,7)$ & $34(69,4)$ & & $23(53,5)$ & $43(75,4)$ & \\
\hline Masculino & $19(37,3)$ & $15(30,6)$ & & $20(46,5)$ & $14(24,6)$ & \\
\hline Idade & & & 0,514 & & & 0,746 \\
\hline 19 a 24 anos & $18(35,3)$ & $13(26,5)$ & & $17(29,8)$ & $14(32,6)$ & \\
\hline 25 a 30 anos & $14(27,5)$ & $18(36,7)$ & & $20(35,1)$ & $12(27,9)$ & \\
\hline 31 a 65 anos & $19(37,2)$ & $18(36,7)$ & & $20(35,1)$ & $17(29,8)$ & \\
\hline Profissão & & & 0,196 & & & 0,748 \\
\hline Equipe enf ${ }^{2}$ & $36(70,6)$ & $40(81,6)$ & & $44(77,2)$ & $32(74,4)$ & \\
\hline Médico/Fisio ${ }^{3}$ & $15(29,4)$ & $09(18,4)$ & & $13(22,8)$ & $11(25,6)$ & \\
\hline Tempo de formação & & & 0,234 & & & 0,749 \\
\hline$\leq 3$ anos & $30(58,8)$ & $23(43,9)$ & & $31(54,4)$ & $22(51,2)$ & \\
\hline$\geq 4$ anos & $21(41,2)$ & $26(56,1)$ & & $26(45,6)$ & $21(48,8)$ & \\
\hline Tempo de trabalho na instituição & & & 0,481 & & & 0,069 \\
\hline 03 a 17 meses & $23(45,1)$ & $27(55,1)$ & & $33(57,9)$ & $17(39,5)$ & \\
\hline$\geq 18$ meses & $28(54,9)$ & $22(44,9)$ & & $24(42,1)$ & $26(60,5)$ & \\
\hline Turno & & & 0,418 & & & 0,310 \\
\hline Diurno & $32(62,7)$ & $25(51,0)$ & & $30(52,6)$ & $27(62,8)$ & \\
\hline Outros $^{4}$ & $19(37,3)$ & $24(49,0)$ & & $27(47,4)$ & $16(37,2)$ & \\
\hline Outro emprego & & & 0,374 & & & 0,148 \\
\hline Sim & $07(13,7)$ & $10(20,4)$ & & $10(23,3)$ & $07(12,3)$ & \\
\hline Não & $44(86,3)$ & $39(79,6)$ & & $33(76,7)$ & $50(87,7)$ & \\
\hline Número de outros empregos & & & 0,486 & & & 0,486 \\
\hline Dois & $03(42,8)$ & $06(60,0)$ & & $05(50,0)$ & $04(57,1)$ & \\
\hline Três & $04(57,2)$ & $04(40,0)$ & & $05(50,0)$ & $03(42,9)$ & \\
\hline
\end{tabular}

${ }^{1} \mathrm{p}<0,05$ para o teste qui-quadrado de Pearson, ${ }^{2}$ Equipe de enfermagem inclui enfermeiros, técnicos e auxiliares de enfermagem, ${ }^{3}$ Médicos e fisioterapeutas, $-{ }^{4}$ Outros: diurno e noturno. 
Também foi identificada resistência à ciprofolaxina $(25,6 \%)$, cloranfenicol $(17,0 \%)$ e gentamicina $(28,7 \%)$, sendo este grupo de antimicrobianos indicado para o tratamento de infecções causadas por SCN, como alternativos. ${ }^{10}$

Os Streptococcus ssp recuperados nos bolsos e região do abdômen não resistiram aos repiques para a realização do antibiograma, possivelmente por necessitarem de condições especiais de cultivos, que podem variar entre as diferentes espécies do gênero, sendo considerados organismos anaeróbicos. ${ }^{11}$
Para a definição dos marcadores de resistência bacteriana seguidos no presente estudo, adotou-se o protocolo estabelecido pela $\mathrm{CCIH}$ da presente instituição, em consonância com o CLSI. Portanto, foram considerados Staphylococcus spp resistentes, aqueles com resistência a oxacilina. ${ }^{10}$

Na Tabela 2, apresenta-se a distribuição dos profissionais participantes do estudo de acordo com as variáveis demográficas em relação à contaminação por Staphylococcus spp resistente a oxacilina.

Tabela 2: Distribuição dos trabalhadores participantes do estudo de acordo com as variáveis demográficas em relação à contaminação por Staphylococcus spp resistente a oxacilina nos jalecos de trabalhadores da saúde em unidades de internação, Divinópolis, 2011.

\begin{tabular}{|c|c|c|c|}
\hline \multirow[b]{2}{*}{ Variáveis } & \multicolumn{2}{|c|}{ Staphylococcus spp resistente a oxacilina } & \multirow[b]{2}{*}{ Valor $\mathrm{p}^{1}$} \\
\hline & $\begin{array}{c}\text { Sim } \\
\mathrm{n}(\%)\end{array}$ & $\begin{array}{c}\text { Não } \\
\text { n (\%) }\end{array}$ & \\
\hline Sexo & & & 0,935 \\
\hline Feminino & $14(60,8)$ & $26(61,9)$ & \\
\hline Masculino & $09(39,2)$ & $16(38,1)$ & \\
\hline Idade & & & 0,038 \\
\hline 19 a 24 anos & $09(21,4)$ & $12(52,2)$ & \\
\hline 25 a 30 anos & $13(31,0)$ & $05(21,7)$ & \\
\hline 31 a 65 anos & $20(47,6)$ & $06(26,1)$ & \\
\hline Profissão & & & 0,035 \\
\hline Equipe de Enfermagem² & $34(81,0)$ & $13(56,5)$ & \\
\hline Médico/Fisioterapeuta & $08(19,0)$ & $10(43,5)$ & \\
\hline Tempo de formação & & & 0,615 \\
\hline$\leq 3$ anos & $21(50,0)$ & $13(56,5)$ & \\
\hline$\geq 4$ anos & $21(50,0)$ & $10(43,5)$ & \\
\hline Tempo de instituição & & & 0,364 \\
\hline$\leq 17$ meses & $17(40,5)$ & $12(52,2)$ & \\
\hline$\geq 18$ meses & $25(59,5)$ & $11(47,8)$ & \\
\hline Turno & & & 0,785 \\
\hline Diurno & $27(64,3)$ & $14(60,9)$ & \\
\hline Outros $^{3}$ & $15(35,7)$ & $09(39,1)$ & \\
\hline Outro emprego & & & 0,537 \\
\hline Sim & $20(86,9)$ & $34(80,9)$ & \\
\hline Não & $03(13,1)$ & $08(19,1)$ & \\
\hline Número de outros empregos & & & 0,621 \\
\hline Dois & $02(66,6)$ & $04(50,0)$ & 0,202 \\
\hline Três & $01(33,4)$ & $04(50,0)$ & \\
\hline
\end{tabular}

${ }^{1} p<0,05$ para o teste qui-quadrado de Pearson. ${ }^{2}$ Equipe de enfermagem inclui enfermeiros, técnicos de enfermagem e auxiliares de enfermagem. ${ }^{3}$ Outros: Noturno e Diurno e Noturno. 
Os membros da equipe de enfermagem tiveram seus jalecos mais contaminamos $(\mathrm{p}<0,05)$ por Staphylococcus spp resistente a oxacilina em relação às demais categorias profissionais, assim como os participantes com idade igual ou superior a trinta e um anos.

Dos microrganismos de importância clínica recuperados dos jalecos de trabalhadores de saúde destaca-se o Acinetobacter baumannii resistente a aminoglicosídeos, cefalosporinas e quinolonas, além do Enterococcus faecalis também resistente aos aminoglicosídeos e quinolonas. Os Staphylococcus aureus, neste estudo, foram apenas resistentes à penicilina.

O isolado de Serratia ssp recuperado no bolso, apresentou resistência ampicilina/sulbactam, aztreonam, cefalotina e ceftazidima.

\section{Discussão}

O jaleco é recomendado para o uso exclusivo dos profissionais nas instituições de saúde durante a assistência a pacientes. O seu uso em ambientes públicos como restaurantes, bares, lanchonete, ônibus, deve ser repensado de forma crítica por parte dos trabalhadores de saúde quanto à possível disseminação de microrganismos na comunidade. ${ }^{12}$

Uneke et al. (2010) registraram em um estudo realizado sobre a possível contaminação de jalecos de médicos na Nigéria que os jalecos de médicos utilizados em locais extra-hospitalares como livrarias e lanchonetes apresentaram maior nível de contaminação em relação a aqueles utilizados somente em locais privativos de assistência. ${ }^{8}$

O uso de jalecos pelos trabalhadores de saúde nas imediações dos estabelecimentos de saúde tornase cada vez mais comum também no Brasil.

Diante disso, tendo em vista a possível participação do vestuário dos trabalhadores de saúde na disseminação de microrganismos, em alguns países como Inglaterra, órgãos governamentais impõem restrições para o uso do jaleco fora dos ambientes hospitalares. ${ }^{13}$

No Brasil, em São Paulo, os trabalhadores da área da saúde estão proibidos de usar jalecos fora do ambiente de trabalho. $\mathrm{O}$ desrespeito a lei estadual de $\mathrm{n}^{\mathrm{o}} 14.466 / 2011$ pode ocasionar multa no valor de cento e setenta e quatro reais e cinquenta centavos (referente a US\$65.31) podendo o valor a ser cobrado duplicar em caso de recorrência. A finalidade da mesma é impedir que jalecos sejam utilizados fora do ambiente hospitalar considerando a possibilidade de que os mesmos sirvam de reservatório e veículo de transmissão de microrganismos podendo acarretar maior contato social favorecendo também a disseminação destes na comunidade. Em Minas Gerais, especificamente Belo Horizonte, foi aprovado à lei municipal de $n^{\circ} 10.136 / 2011$, que proíbe o uso do jaleco nas ruas da cidade, o estado do Mato Grosso do Sul, Maceió e Paraná também decretaram leis similar. ${ }^{14,15}$

A fiscalização destes decretos fica a cargo das Secretarias de Saúde de cada estado ou município, por enquanto, as infrações as legislações não estão tendo efeito punitivo, e, não tem sido cumprida pelos trabalhadores da área da saúde. As Secretarias de Saúde ainda afirmam que campanhas educativas são necessárias para uma melhor conscientização e adesão a lei em cada região do país.

Tais medidas se fundamentam nos achados de estudos que avaliaram a presença de microrganismos em jalecos dos trabalhadores de saúde indicando que estes são frequentemente contaminados por microrganismos como os Staphylococcus aureus, Acinetobacter baumannii, Klebsiela pneumoniae, Serratia rubidae, destacando-se ainda a importância clínica e epidemiológica dos mesmos. ${ }^{11,14}$

As áreas dos jalecos com maior contaminação apontadas em diversos estudos têm sido os bolsos, região do abdômen pelo possível contato direto destes locais com as mãos dos profissionais, com os pacientes durante a assistência ou contato indireto com superfícies ambientais, estetoscópios, equipamentos, instrumentos clínicos, entre outros. ${ }^{6,7,16}$

Além disso, jalecos submetidos a menor frequência de troca e lavagem tendem a apresentar-se mais contaminados, ou seja, o maior tempo de uso pode apresentar uma relação direta com o aumento da contaminação. 6,7

No presente estudo, a contaminação na região o abdômen esteve associada ao sexo, os jalecos dos profissionais do sexo feminino apresentaram-se mais contaminados. Destaca-se que a maior parte dos trabalhadores participantes eram técnicos de enfermagem, profissão esta conhecida como tendo maior número de profissionais do sexo feminino. ${ }^{17}$

Nos jalecos dos trabalhadores de saúde da instituição em questão, diversas espécies de Staphylococcus ssp foram isoladas.

Dentre as espécies, o Staphylococcus aureus é o mais importante patógeno podendo estar associado a graves infecções em pacientes hospitalizados e também na comunidade. ${ }^{18,19}$ Em apenas um jaleco anali- 
sado nesta pesquisa, foi recuperado Staphylococcus aureus na região do abdômen.

Por outro lado, os Staphylococcus coagulasenegativa têm emergido como um dos principais agentes etiológicos causadores das IRAS, sendo o Staphylococcus epidermidis o mais prevalente ${ }^{19}$, encontrado de forma predominante em 37,23\% das 94 amostras positivas do presente estudo.

Até a década de 1970, os SCN eram reportados como microrganismos, de importância clínica secundária e raramente mencionados como agentes de infecções graves. A partir da década de 80, esses patógenos passaram a ser reconhecidos como causadores de septicemia, especialmente em pacientes neonatal e pediátrico. ${ }^{20}$

O aumento do uso de dispositivos intravasculares, assim como do número de pacientes imunocomprometidos hospitalizados contribuem para a emergência de infecções da corrente sanguínea, sendo os $\mathrm{SCN}$ os principais microrganismos causadores. ${ }^{20}$

Nos Estados Unidos o Staphylococcus epidermidis e outros SCN são responsáveis por $31 \%$ das infecções de corrente sanguínea respectivamente. No Brasil, este percentual é muito próximo de $29 \%$ podendo variar de acordo com o estabelecimento de saúde, a especialidade e o tempo de internação do paciente. ${ }^{19}$

Uma característica importante dos SCN é a resistência aos agentes antimicrobianos que favorece a sua permanência no ambiente hospitalar, seja pela sua capacidade de formação de biofilme, que se apresenta como uma barreira física impossibilitando a ação dos antibióticos, ou pela sua sobrevivência em ambientes e equipamentos por dias, semanas ou meses. ${ }^{21}$

O biofilme consiste em colônias microbianas que aderidos a uma superfície multiplicam-se. Normalmente, estão embebidos por uma matriz polimérica extracelular, sendo os polissacarídeos principais componentes. ${ }^{21} \mathrm{~A}$ formação de biofilme pelos microrganismos resulta em uma fonte continua de disseminação de patógenos.

No estudo realizado o Staphylococcus epidermidis resistentes à oxacilina é apontado como o segundo microrganismo relacionado à ocorrência de IRAS.

Cabe destacar ainda a resistência a ciprofloxacina $(25,53 \%)$, cloranfenical $(17,03 \%)$ e gentamicina $(28,73 \%)$. A ocorrência de resistência neste grupo de antimicrobianos merece atenção, uma vez que, estes estão recomendados para o tratamento de infecções causadas por SCN, como alternativos ou secudários. A ocorrência de resistência neste grupo possivelmente esta relacionada ao uso indiscriminado para o tratamento das infecções. ${ }^{11}$

Quanto aos fatores relacionados à ocorrência de contaminação por $\mathrm{SCN}$ resistentes à oxacilina nas áreas dos jalecos analisadas a variável profissão e idade foi estatisticamente significativa $(\mathrm{p}<0,05)$. Esse resultado permite inferir que a categoria de profissionais que têm maior contato com paciente, neste caso os da equipe de enfermagem, predispõe a ocorrência de contaminação.

O predomínio de Acinetobacter baumannii na região do abdômen pode estar relacionado com maior contato desta região com superfícies e equipamentos.

A recuperação de Enterococcus faecalis de jalecos de trabalhadores de saúde na região do abdômen sugere a provável contaminação durante procedimento como banho, manipulação de excreções corporais, troca de roupa de cama, uma vez que estes são patógenos que colonizam o trato gastrointestinal.

Quanto às medidas de controle da disseminação de microrganismos e da resistência bacteriana, destaca-se ainda a importância da maior ênfase na higienização das mãos para os profissionais, considerando que esta é a principal via de disseminação. ${ }^{4,5}$

Geralmente as medidas de controle das infecções têm como um dos focos principais os cuidados com procedimentos invasivos (no momento da realização e manutenção dos mesmos) o longo período de internação do paciente entre outros, podendo na maioria das vezes subestimar a participação do ambiente hospitalar e dos jalecos utilizados pelos trabalhadores de saúde na cadeia de disseminação de microrganismos.

Diante dos resultados obtidos, sugere-se maior investimento em programas de educação permanente, voltadas para os aspectos de biossegurança, disseminação de microrganismos, bem como o papel dos fatores ambientais sendo imprescindível a inclusão do jaleco como potencial reservatório de microrganismos.

\section{Conclusão}

Foram obtidas 200 amostras de jalecos de trabalhadores de saúde, dos quais 94 (47\%) apresentaram crescimento microbiano, sendo que $73,6 \%$ dos microrganismos isolados apresentaram resistência a um ou mais antimicrobiano testado. As espécies de importância clínica isoladas foram Staphylococcus 
ssp, Enterococcus faecalis, Acinetobacter baumannii, Streptococcus ssp, Serratia ssp. Os bolsos apresentaram maior contaminação em relação à região do abdômen.

Recomenda-se maior investimento em programas de educação permanente voltadas para os aspectos de biossegurança, adesão a higienização das mãos, papel do ambiente e dos jalecos como potenciais reservatórios de microrganismos susceptíveis e resistentes. Além disso, investir no treinamento dos trabalhadores de saúde apontando a indicação do uso, cuidados com o armazenamento e frequência de troca dos jalecos.

\section{Referências}

1. World Health Organization. WHO guidelines on Hand Hygiene in Health Care. First Global Patient Safety Challenge Clean Care is Safer Care. Geneva: WHO; 2009. 270p.

2. BRASIL. Ministério da Saúde. Agencia Nacional de Vigilância Sanitária. Brasil enfrenta infecções em serviços de saúde. Disponível em: http://portal.anvisa.gov.br. Acesso em 30 de Abril de 2010.

3. Hautemanière A, Florentin A, Hartemann P, Hunter PR. Identifying possible deaths associated with nosocomial infection in a hospital by data mining. Am J Infect Control. 2011; 39: 118-22.

4. Siegel JD, Rhinehart E, Jackson M, Chiarello L. Healthcare Infection Control Practices Advisory Committee (HICPAC). Guideline for isolation precautions: preventing transmission of infectious agentes in healthcare settings. Atlanta, GA: Centers for Disease Control and Prevention; 2007.

5. Haas JP, Larson EL. Measurement of complicance with had hygiene. J Hosp Infect. 2007; 66:6-14.

6. Treakle AM, Thom KA, Furano JP, Strauss SM, Harris AD, Perencevich EN. Bacterial contamination of health care workers' white coats. Am J Infect Control. 2009; 37:101-5.

7. Gaspard P, Eschbach E, Gunther D, Gayet S, Bertrand X, Talon D. Meticillin-resistant Staphyococcus aureus contamination of healthcare workers' uniforms in long-term care facilites. J Hosp Infect. 2009; 71:170-5.

8. Pilonetto M, Rosa EAR, Brofman PRS, Baggio D, Calvário F, Schelp C, et al. Hospital Gowns as a Vehicle for Bacterial Dissemination in an Intensive Care Unit. Braz J Infect Dis. 2004; 8:206-10.

9. Uneke CJ, ljeoma PA. The potencial for nosocomial infection transmission by white coat used by physicians in Nigeria: Implications for improved patient-safety initiatives. Would Health \& Population. 2010; 11:44-54.
10. Gaspard P, Eschbach E, Gunther D, Gayet S, Bertrand X, Talon D. Meticillin-resistant Staphyococcus aureus contamination of healthcare workers' uniforms in long-term care facilites. J Hosp Infect. 2009; 71:170-5.

11. Clinical and Laboratory Standards Institute (CLSI. Performance standards for antimicrobial disk susceptibility tests; approved standard - tenth edition. CLSI document M10-S19. Wayne, PA: Clinical and Laboratory Standards Institute; 2009.

12. Molinaro EM, Caputo LFG, Amendoeira MRR. Conceitos e métodos para a formação de profissionais em laboratórios de saúde. Rio de Janeiro: Fundação Oswaldo Cruz; 2009. $460 p$.

13. Oliveira AC, Damasceno QS, Ribeiro SMCP. Infecções relacionadas à assistência em saúde: desafios para prevenção e controle. REME Rev Min Enferm. 2009;13: 445-50.

14. Dancer SJ. Pants, policies and paranoia. J Hosp Infect. 2010; 74: $10-15$

15. Cuminale N. São Paulo proíbe uso do jaleco fora do hospital. Veja 10 Jun.2011. Disponível em: www.veja.abril.com.br. [Acesso em 01 de Setembro de 2011].

16. Silva R. Proibido uso de jalecos nas ruas de Belo Horizonte. A província 23 de Dezembro/2010. Disponível em: reginauro.blogspot.com [acesso em 10 de Março de 2011].

17. Askarian M, Aramesh K, Paleni CJ. Knowledge, attitude, and practice toward contact isolation precautions among medical students in Shiraz, Iran. Am J Infect Control. 2006; 34: 593-6.

18. Wiener-Well Y, Galuty M, Rudensky B, Schlesinger Y, Attias D, Yinnon AM. Nursing and physician attire as possible source of nosocomial infections. Am J Infect Control. 2011; 39:555-9.

19. Rigatti F, Tizotti MK, Hörner R, Domingues VO, Martini R, Mayer LE et al. Bacteremias por Staphylococcus Coagulase negativos oxacilina resistentes em um hospital escola na cidade de Santa Maria, Estado do Rio Grande do Sul. Rev Soc Bras Med Trop. 2010; 43:686-90.

20. Padoveze MC, Assis DB, Freire, MP, Madalosso G, Ferreira, AS, Valente, MG, Fortaleza, CMCB. Surveillance Programme for Healthcare Associated Infections in the State of São Paulo, Brazil. Implementation and the first three years' results. J Hosp Infect. 2010; 76:311-15.

21. Blum-Menezes D, Bratfich OJ, Padoveze MC, Moretti ML. Hospital strain colonization by Staphylococcus epidermidis. Braz J Med Biol Res. 2009; 42: 294-8.

22. Klingenberg C, Ronnestad A, Anderson AS, Abrahamsem TG, ,Zorman J,Villaruz LE, et al. Persistent strains of coagulasenegative staphylococci in a neonatal intensive care unit: virulence factors and invasiveness. Clin Microbiol Infect. 2007; 13: $1100-11$ 